\title{
A Question of Balance: A Qualitative Study of Mothers' Interpretations of Dietary Recommendations
}

\author{
Fiona Wood, PbD \\ Michael Robling, $\mathrm{PbD}$ \\ Hayley Prout, BA \\ Paul Kinnersley, MD \\ Helen Houston, MD \\ Christopher Butler, MD \\ Department of Primary Care and Public \\ Health, School of Medicine, Cardiff Uni- \\ versity, Neuadd Meirionnydd, Heath Park, \\ Cardiff, Wales
}

\begin{abstract}
PURPOSE Poor nutrition is an increasing problem for economically deprived families, and mothers play a key role in establishing children's diets. We explored mothers' understanding of health-promotion recommendations for healthy eating.

METHODS We conducted qualitative semistructured interviews of 46 mothers within a relatively socioeconomically deprived community. Data were subject to framework analysis.

RESULTS The basic slogans of health promotion were known by mothers and had been adopted into everyday language. Television was the main source of information on dietary advice. Barriers to making changes were due to practical constraints (time, money, family preferences) and a desire to enhance quality of life through enjoyment of food. Although the headline messages of the importance of a healthy diet and what constitutes a healthy diet had reached mothers, misunderstandings were common and led to inappropriate actions. Many descriptions of what mothers reported as a balanced diet would not satisfy official definitions. Some women willfully adapted their understanding of advice to suit their preferences and the reality of their lives and family circumstances.
\end{abstract}

CONCLUSIONS To provide effective advice and guidance, health professionals need a deeper understanding of how families interpret messages about healthy eating. In addition, they should provide advice based on more individual understandings of diet and take into account patient preferences and life circumstances.

Ann Fam Med 2010;8:51-57. doi:10.1370/afm.1072.

\section{INTRODUCTION}

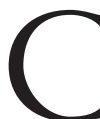
oncerns about obesity and poor health relating to poor diet continue to be expressed in most industrialized nations. ${ }^{1,2}$ By 2050, $60 \%$ of men and $50 \%$ of women within the United Kingdom could be clinically obese, and the associated health service costs could be $£ 10$ billion (US $\$ 14$ billion) per year. ${ }^{3}$

Dietary advice from health care personnel has been effective in achieving only modest dietary change. ${ }^{4-6}$ Even so, small changes throughout a population may be quite effective. Many individuals find it difficult to comply with recommended dietary changes provided in individual dietary counseling. ${ }^{7}$ Furthermore, dietary advice interventions can be intensive and costly. 8,9

Social learning theory suggests that such behaviors as diet can be learned by observing the behavior of others and that behaviors are either reinforced or discouraged on the basis of observed outcomes. ${ }^{10}$ Social learning theory also suggests that lasting behavior change is more likely if the proposed change is considered important, and individuals are confident that change is feasible. ${ }^{11}$ There are a number of reasons why people may not or cannot change their diet, including convenience, lim- 
ited resources, and cooking skills. ${ }^{12-14}$ An alternative explanation for poor uptake of dietary advice is that individuals themselves do not perceive their diet to be particularly unhealthy or at odds with official advice and therefore do not consider changing their diet. ${ }^{15-17}$ Individuals may believe that change is important and that they have already made adequate changes, but in fact, they have misinterpreted or inadequately adapted dietary advice. To inform health professionals and increase their ability to provide effective help to patients, we explored how dietary advice has been interpreted by the lay public.

\section{METHODS}

We used qualitative semistructured interviews to elicit understandings (and misunderstandings) of what constitutes a healthy diet. Given the importance of mothers as mediators of family health, ${ }^{18}$ we interviewed mothers of children aged 16 years or less. We focused on an area of relative socioeconomic deprivation, because families from lower socioeconomic groupings generally have poorer health and are more likely to engage in health-threatening behavior. ${ }^{19}$

The research was conducted within Llanedeyrn, a community located close to the city center of Cardiff, South Wales. Built during the 1960s, Llanedeyrn was composed of state-supported and privately owned homes to accommodate approximately 7,000 people. The socioeconomic status of communities in the United Kingdom is based on a Townsend score, which has 4 variables: unemployment (lack of material resources and insecurity), overcrowding within the home (poor living conditions), lack of owner-occupied housing (lack of wealth), and lack of car ownership (low income). The Townsend score placed Llanedeyrn in the fourth quintile of deprivation in Wales; that is, if all Welsh communities were ranked according to the score and then divided into fifths, Llanedeyrn would rank in the second lowest $20 \%$, an indication of relative but not extreme socioeconomic deprivation. One health center is the provider of family medicine to the community. Several studies on healthy lifestyles conducted in Llanedeyrn in the $1980 \mathrm{~s}^{20-23}$ found that few women from the community prioritized healthy lifestyles.

\section{Recruitment}

Following approval from the local medical ethics review committee, mothers fulfilling the inclusion criteria (with a child under 16 years, living within the community) were selected at random from a health center's age-sex register and sent a letter of invitation signed by a family doctor (P.K.) with an information sheet about the study. Mothers were encouraged to return a reply-slip to the research team. Recruitment was slow using this method, however, and approval was given by the ethics review committee to use 3 additional methods. The first involved the researcher (H.P.) attending 2 community centers in the area (meeting points for mother and toddler groups) to inform potential participants about the study. The second involved an opportunistic approach by receptionists at the health center inviting potential participants to learn more about the study. Lastly, 2 participants were recruited using snowball sampling (the researcher left her office number with participants so they could pass it onto local friends).

\section{Data Collection}

Social learning theory was used as a theoretical basis because we were interested in how mothers viewed the importance and feasibility of health behavior change and how they accessed and interpreted information about family diet. ${ }^{10}$ Our interview guide therefore focused on participants' beliefs about what facilitates good health, perceived responsibility for health, perceived importance of making healthy lifestyle changes, sources of dietary advice, family diet, and constraints to healthy eating. Conversation was allowed to develop naturally between the researcher and participant while ensuring that main topics were explored in sufficient depth. Interviews were conducted in the participants' own home $(n=21)$, in a private room in the health center $(n=19)$, or in a private room within the local community center $(n=6)$. Each participant received a supermarket voucher worth $£ 20$ (US \$29) in recognition of her time and contribution. Interview length ranged from 30 to 72 minutes. All interviews were audio recorded and transcribed verbatim with some personal information deleted to preserve anonymity and confidentiality. All participants signed a consent form before the interview. The participants were also asked to provide some information about their occupation and their partner's occupation to determine their social class.

Our research team consisted of 3 family doctors (C.B., P.K., H.H.) who have practiced family medicine in Llanedeyrn and were familiar with the problems facing families in the community. These family doctors also held university posts and had a professional interest in health behavior change. Two social scientists led the research team (FW., a sociologist, and M.R, a health psychologist), both of whom have more than 10 years of qualitative research experience. All the interviews were conducted by a female research nurse (H.P.), who also had extensive experience with qualitative interviewing. She had not previously worked in the community and so was not known to mothers in this study. 


\section{Data Analysis}

Data analysis was primarily led by 2 researchers, with additional input by and discussion with coauthors. Data were analyzed according to the methods of framework analysis. ${ }^{24}$ The technique involves 5 stages. The first 3 stages, familiarization, identifying a thematic framework, and indexing, are common to other forms of qualitative data analysis. Familiarization was achieved through repeated readings of each transcript by 2 or more members of the research team. A thematic framework was developed by generating thematic categories, forming superordinate categories that grouped themes together and subordinate categories that broke themes into finer detail. Regular team meetings were held to discuss and refine the thematic framework. Indexing was accomplished by coding lineby-line sections of data to the thematic framework, with reliability checked by a second researcher who indexed $33 \%$ of the interviews.

The fourth stage of framework analysis, charting, involved arranging summaries of the data in a database according to thematic content listed by case. This fourth stage enabled the research team to view a range of data across cases and by theme. The final stage, mapping and interpretation, allowed the research team to compare and contrast participants' accounts while searching for explanations for patterns in the data. We also explored whether dietary beliefs and behaviors of mothers from the higher social class category (social class II) differed from the accounts of dietary beliefs and behavior of other mothers in the sample.

Although the interview schedule covered a number of topics, including perceived responsibility for health and perceived importance of making healthy lifestyle changes, we focus this report on the key issues that were mapped from the framework analysis relating to mothers' awareness of healthy eating messages, barriers to making lifestyle changes, and interpretations of healthy eating messages.

\section{RESULTS}

Forty-six interviews were conducted between January and September 2006 (Table 1). The social class (based on the United Kingdom's Registrar General's social class classification system and thus an indicator of an individual family's socioeconomic status) and age-group of the participants are outlined in Table 2.

Quotes in the text also provide basic demographic information about the participant. The quotes were selected to illustrate the main points while also reflecting views from a range of participants.

\section{Awareness of Healthy Eating Messages}

When asked about the main reasons for ill-health, 32 of the 46 mothers mentioned poor diet. The basic slogans of health promotion in relation to diet were known by these mothers and had entered into their everyday language. For example, all participants mentioned that fruit and vegetables were part of a healthy diet, and some $(\mathrm{n}=15)$ spontaneously quoted the 5-a-day recommendation (a UK public health message that people should eat 5 portions of fruit or vegetables daily). Knowledge of nutrition was superficial, however, and the discussion rarely went beyond an acknowledgment that fruit and vegetables were healthy food. Indeed, as the quote from participant 7 suggests, this slogan was sometimes seen as impractical and thus a joke. Only 3 participants raised the topic of whole grain or brown food (although only 1 of these appeared to purchase whole grain food), and 2 mothers made reference to the importance of alternative cooking methods (grilling rather than frying, or steaming rather than boiling).

So what would you say the healthy foods are (Researcher)?

Well it's like your 5-a-day lark [joke], isn't it (Participant 7: social class IV, age 36 years, married, children aged 9, 11, and 14 years)?

I have a mother-in-law who is diabetic, and they [doctors] were telling her the foods she should eat. Brown things you should eat. The brown things are good for you (Participant

\begin{tabular}{|lc|}
\hline \multicolumn{2}{|c|}{ Table 1. Method of Recruitment $(\mathbf{N}=\mathbf{4 6})$} \\
\hline Recruitment Method & No. Recruited \\
\hline Letters of invitation drawn from practice age/ & $17^{\mathrm{a}}$ \\
sex register & 18 \\
Community centres & 9 \\
Reception desk at health centre & 2 \\
Snowballing & \\
\hline
\end{tabular}

Table 2. Age and Social Class of Participants $(\mathrm{N}=46)$

\begin{tabular}{lccc}
\hline Social Class & $\begin{array}{c}\text { Aged } \leq 30 \text { y } \\
\text { No. }\end{array}$ & $\begin{array}{c}\text { Aged }>30 \text { y } \\
\text { No. }\end{array}$ & $\begin{array}{c}\text { Total } \\
\text { No. (\%) }\end{array}$ \\
\hline I: Professional occupations & 0 & 0 & $0(0)$ \\
II: Managerial and technical occupations & 4 & 5 & $9(20)$ \\
IIIN: Skilled occupations (nonmanual) & 3 & 6 & $9(20)$ \\
IIIM: Skilled occupations (manual) & 3 & 10 & $13(28)$ \\
IV: Partly skilled occupations & 3 & 4 & $7(15)$ \\
V: Unskilled occupations & 6 & 2 & $8(17)$ \\
Total & 19 & 27 & $46(100)$ \\
\hline
\end{tabular}


19: social class IV, aged 23 years, married, children aged 3 and 4 years).

Television was by far the most frequently mentioned source of information about diet, with mothers referring to numerous prime-time programs that discuss family nutrition and that had provided these mothers with a stimulus for learning about food and nutrition.

Like this Jamie Oliver [celebrity television chef], he's made people sort of sit up and think, oh yeah what is going on, what is going into our food and all that. So I think people are more aware (Participant 11: social class IV, age 38 years, divorced, children aged 5, 6, 10, and 14 years).

A number of mothers were proud of their responsible attitudes to family nutrition, with some explaining in great detail how they planned and prepared family meals. Although these mothers clearly tried to provide healthy food, their descriptions of the actual food were at odds with official recommendations for healthy eating. For example, their accounts indicate an assumption that hot, filling, and appetite-satisfying food was generally healthy food.

I'll make sure there's Sunday dinner on the table, every Sunday guaranteed. They will have chips once a week and then they will have a cooked dinner in the week as well. I'll try and do a Bolognese, or do some type of pasta dish. And so I try and make sure that they get plenty of veg, at least twice a week if I can (Participant 8: social class IV, age 35 years, lives with her partner, children aged 2 months, 15 , and 21 years).

\section{Barriers to Making Dietary Changes}

Although most mothers $(n=32)$ stated that an unhealthy diet was one of the main reasons for poor health, they also recognized that their diet was often unhealthy. Individual responsibility for diet and health was resisted by mothers who stressed the importance of personal choice and pleasure above the nutritional value of their family's diet. A reduction in immediate quality of life was perceived to be the downside to healthy eating. Personal preference and pleasure were valued above government advice. Indeed, health promotion advice was sometimes mocked for its austerity. Bad food was acknowledged as generally bad for physical health, but it was also viewed as a treat that one earns at the weekend or after a hard day's work and thus normalized as part of everyday life. Good food was discussed as flavorless, boring, and associated with self-denial. Self-admonishments of irresponsibility were also accompanied by reasoned explanations Mothers from across the range of social class categories saw eating foods that could be considered a poor diet as a coping strategy that could serve to improve other aspects of family well-being.
Okay, and what do you think is a good diet (Researcher)?

All the things that don't taste so good, well, fresh things, fish, vegetables, fruit (Participant 27: social class IIIN, age 26 years, married, children aged 3 and 5 years).

It's a short life that we lead, and I think if you haven't got a little of a vice in your life, it's a bit boring, isn't it? (Laughs) I mean, you know, you can't be like, what's the name, uhm, that woman on "You Are What You Eat" [a UK television program]. Blimey! I'd kill myself, I think, if I had to eat that diet all the time (laughs) (Participant 10: social class II, age 35 years, single, child aged 7 years).

Our participants described practical constraints on making changes to their diet. The most frequently reported obstacles were limited time, money, cooking skills, and restrictions on the availability of healthy food close to home. The emphasis was on convenience. Partners and children also constrained food choices and forced mothers to compromise between their notions of nutritional adequacy and the family's food preferences.

\section{Interpretations of Healthy Eating Messages}

Although possessing a basic understanding of healthy and unhealthy food, we found that mothers in the sample had misunderstood information about some aspect of the food or about how to incorporate healthy changes into their eating habits. In comparison with other lifestyle behaviors, such as smoking, where the message is clear that smoking under any circumstances is unhealthy, promotion of healthy eating is complex. The mothers in our sample struggled to make sense of how to eat healthily. For example, one mother had thought she had given her child a healthy natural drink but in so doing had unknowingly given her child a drink with a high sugar content.

When [daughter] was a baby, I always gave her the fennel drink because I was told that was really good for them, but she lost all her teeth, well she lost half of them, they'd all rotted and I couldn't understand why... and the dentist said it could be down to this fennel drink she was having. It's just like, well, it's supposed to be natural and it just is, it's just basically like giving them a natural sort of drink (Participant 11: social class IV, age 38, divorced, children aged 5, 6, 10 and 14).

Other mothers (including mothers from social class II) were also confused about more complex aspects of diet and how it might affect their families' health.

I know what's classed as healthy and unhealthy food, but there's a lot of things, like margarines and butters and things like that,... low in saturates, polyunsaturates. What's that? It's just a word unless you know what they actually mean and 
what it can cause (Participant 45: social class V, age 29 years, single, 3 children aged 4,7 and 9 years).

I know it is natural sort of food as you think of as healthy foods. But I think we've been misled as well a lot with food, you know? And now we've been told we've got to start eating fats, that there are good fats as well as bad fats (Participant 32: social class II, aged 40 years, married, children aged 15 and 6 years)?

Ten of the 46 mothers spontaneously mentioned balanced diet. It emerged, however, that at least 5 of these 10 mothers had misinterpreted the generalized message of the importance of eating a diet that is balanced. This concept, according to official health promotion recommendations, involves a diet incorporating the major food groups and providing the body with the variety of nutrients needed for good health. Instead, the mothers' interpretation incorporated the notion of balancing good food with bad food and was therefore very different from official definitions, although both definitions of balance (spread and equilibrium) could be valid.

Like I say, I do eat rubbish, but, I always balance it with a lot of fruit and veg, so it's a very balanced diet, I mean I eat a lot of it but it's a lot of balanced stuff (Participant 10: social class II, age 35 years, single, child aged 7 years).

...loads of chocolate and crisps so he has to have you know, yeah, we all eat pretty good you know, we steam all our veg and yeah, so we don't eat too bad. Obviously we have our take-aways and our junk and things in between but, its okay, it's fine, it's a balanced diet (Participant 1: social class IIIM, age more than 34 years, married, children aged 4 and 12 years).

Although only 10 mothers actually mentioned the term balance when discussing their diet, analysis of data showed that other mothers were thinking about their lifestyles in terms of balancing bad with good. Participant 31, who admitted she is overweight, shows in her rationalization of her activities that indulging in the bad behavior was merited on the basis of some corresponding good behavior.

I'm addicted to bacon lately. I smell bacon and want it. I think that's because there's nothing really for people to do. But it's like bloatiness and you know, drab and you feel depressed anyway if you eat the wrong things. Yeah an iffy tummy. I do regret it afterwards (Participant 31: social class $V$, age 27 years, married, children aged 3, 4, 6, 7, and 9 years).

Do you (Researcher)?

I try and make myself better when I have a bacon sandwich, I have salad with it. If I have a salad one, I'm not so bad. I think it's my mind playing tricks on me (Participant 31).

\section{And similarly later on in the interview:}

I go to the pub [public house or local bar] because they got music on a Friday night. The bad thing is I have a drink (Participant 31).

Right (Researcher).

But the good thing as well, I walk home (Participant 31).

These quotes indicate that the mother is aware of the activities that have the potential to improve or damage her health. Although her feelings of guilt appear to be admonished by pairing good with bad behaviors, however, it is unlikely that small-scale attempts to improve her health, such as walking home, can completely redress any potential damage done by an evening drinking.

Official health promotion messages had also been re-molded to make them more acceptable to the recipient. In some instances, poor diet was being reinforced by personal observations.

I used to be a takeaway freak (laughs). I can't be bothered cooking, I'll just get a takeaway (Participant 18: social class IV, age 37 years, lives with her partner, child aged 14 years).

What do you think of takeaways (Researcher)?

Uhm, well, I think, I mean, I eat lot of Chinese takeaway, which I think is quite healthy anyway, because they, I mean you rarely ever see a fat Chinese person. A lot of Indian foods are quite high in fat (Participant 18).

Advice about diet and nutrition, received from a variety of agencies including the media, is therefore being personally modified to make it more acceptable to the recipient.

\section{DISCUSSION}

Although the main messages of the importance of a healthy diet and what constitutes a healthy diet have clearly reached mothers living in an area of relative socioeconomic deprivation, the messages are being interpreted in a superficial way and appear ineffective. Eating 5-a-day and eating a balanced diet were the most commonly reported dietary slogans, although there were others, such as natural foods are good. In our sample, improved awareness of healthy eating was fueled by the popular media, in particular television. Misinterpretations of health promotion messages were particularly evident in relation to what constitutes natural food and a balanced diet. Furthermore, our data indicate that mothers see enhancing quality of life as a greater immediate priority than investing in good health. 


\section{Strengths and Limitations}

The interviews functioned as opportunities for the participants to rationalize their own beliefs and behaviors and to present themselves to the researcher as responsible mothers. ${ }^{25}$ This problem of social desirability bias would not have been resolved had we used an alternative method of data collection. Furthermore, face-to-face interviews did allow us to probe the veracity of participants' reported beliefs and behaviors, for example by exploring contradictory statements.

All the participants interviewed lived within an area of relative socioeconomic deprivation, but 9 of the mothers were more prosperous (socioeconomic group II). Although we interviewed only a few women from some social class categories, we found no major differences in knowledge of what constitutes a healthy diet and interpretations of dietary messages between social classes. We therefore tentatively suggest that the socioeconomic circumstances of the community that one lives in may influence dietary knowledge more than personal socioeconomic status.

We did not collect data on the actual income because we believed that such questions might be considered intrusive. Data on educational attainment of the participants would have been useful.

\section{Comparison with Existing Literature}

Our study builds on research conducted on mothers in the same community in the 1980 s. $^{20-23}$ At that time, few mothers in Llanedeyrn prioritized healthy lifestyles. One important change is the increasing belief among mothers that a good diet is of fundamental importance to good health; however, the misunderstanding of what a good diet means eliminates the benefits obtained.

Other studies have described how families living in relative socioeconomic deprivation are resistant to making dietary changes because of economic reasons and time constraints, ${ }^{12,13}$ or that healthy food is considered as bland and unsubstantial. ${ }^{26}$ Although a number of studies have evaluated the impact of dietary advice interventions, ${ }^{4-6}$ how basic dietary messages are interpreted by patients who are resistant to behavior change has not been addressed adequately in the literature.

\section{Implications for Future Research or Clinical Practice}

Health professionals provide, and individuals are expected to act on, health promotion messages in their everyday life. The improvement in awareness of healthy diet may be considered positive. Health behavior change is unlikely to occur unless preceded by awareness that change is important. Whereas most mothers in the study saw healthy eating as important to good health, only some were confident they could make healthy changes, and some believed, incorrectly, that they had made appropriate changes. Confused interpretations limit people's ability to bring about lifestyle change. Current generic slogans, such as 5 -aday or eat a balanced diet, are useful starting points; even so, it is clear that detailed advice on how changes can be positively achieved and sustained is not filtering through to the public. To manage the potential misinformation and modification of public health messages by their patients, clinicians should be aware of not only these public health messages but also how their patients are understanding and applying them in their lives. Clinicians need to make more detailed assessment of their patients' eating habits ${ }^{27}$ and reinforce healthy eating messages with more personalized communication. In so doing, they could address issues of how to deal with the family's expectations of what constitutes a proper meal and how fruit and vegetables can be more easily and cheaply incorporated into the family diet. Focusing on improving mothers' understandings of a good diet is likely to have an impact on the wider family. Public health campaigns also need to take account of the way people live and think about their eating. Perhaps not surprisingly, simply being exposed to public health messages is not enough to achieve lasting behavior change.

To read or post commentaries in response to this article, see it online at http://www.annfammed.org/cgi/content/full/8/1/51.

Key words: Great Britain; qualitative research; diet; health promotion; risk reduction behavior

Submitted December 19, 2008; submitted, revised, May 22, 2009; accepted June 12, 2009.

Portions of this study were presented at the meeting of the South West Society for Academic Primary Care, Warwick, UK, March 2008.

Funding support: The study was funded by the Economic and Social Research Council (reference RES000221345). The funding body has no involvement in the authors' work.

Acknowledgments: We wish to acknowledge the contribution of the 2 community representatives on the study team (Kathyrn Underhill and Julia Burnham). We are grateful to staff at Llanedeyrn Health Centre and the community centers of The Powerhouse and The Dome who helped facilitate recruitment of participants to the study. We would also like to thank Professor Nigel Stott and Professor Roisin Pill, who provided advice on the conduct of this study. We also thank the reviewers for their constructive feedback.

\section{References}

1. The Audit Commission, The Healthcare Commission, National Audit Office. Report by the Comptroller and Auditor General. Tackling Child Obesity: First Steps. Report by the Comptroller and Auditor General. London, HC 801 Session 2005-2006. 28 February 2006.

2. Kmietowicz Z. MPs deplore poor progress in combating childhood obesity. BMJ. 2007;334(7586):173. 
3. McPherson K, Marsh T, Brown M. Tackling obesities: future choices - modelling future trends in obesity and its impact on health. Report for Foresight Government Office of the Chief Scientist. http://www.foresight.gov.uk. 2007.

4. Brunner EJ, Rees K, Ward K, Burke M, Thorogood M. Dietary advice for reducing cardiovascular risk. Cochrane Database Syst Rev. 2007;(4):CD002128.

5. Lemmens VE, Oenema A, Klepp KI, Henriksen HB, Brug J. A systematic review of the evidence regarding efficacy of obesity prevention interventions among adults. Obes Rev. 2008;9(5):446-455.

6. Ashenden R, Silagy C, Weller D. A systematic review of the effectiveness of promoting lifestyle change in general practice. Fam Pract. 1997;14(2):160-176.

7. Tang JL, Armitage JM, Lancaster T, Silagy CA, Fowler GH, Neil HA. Systematic review of dietary intervention trials to lower blood total cholesterol in free-living subjects. BMJ. 1998;316(7139):1213-1220.

8. Lindström J, Louheranta A, Mannelin M, et al; Finnish Diabetes Prevention Study Group. The Finnish Diabetes Prevention Study (DPS): Lifestyle intervention and 3-year results on diet and physical activity. Diabetes Care. 2003;26(12):3230-3236.

9. Roux L, Kuntz KM, Donaldson C, Goldie SJ. Economic evaluation of weight loss interventions in overweight and obese women. Obesity. 2006;14(6):1093-1106

10. Bandura A. Social Learning Theory. London: Engelwood Cliffs, 1977.

11. Rollnick S, Miller R, Butler C. Motivational Interviewing in Health Care: Helping Patients Change Behaviour. New York, NY: Guildford Press; 2008.

12. Murcott A. Understanding life-style and food use: contributions from the social sciences. Br Med Bull. 2000;56(1):121-132.

13. Department of Health. Food Action Plan. London: Department of Health; 2003.

14. Department of Health. Choosing Health: Making Healthier Choices Easier. London: Department of Health; 2004

15. Kearney JM, McElhone S. Perceived barriers in trying to eat healthier-results of a pan-EU consumer attitudinal survey. Br J Nutr. 1999; 81(Suppl 2):S133-S137.
16. Kearney JM, Gibney MJ, Livingstone BE, Robson PJ, Kiely M, Harrington K. Attitudes towards and beliefs about nutrition and health among a random sample of adults in the Republic of Ireland and Northern Ireland. Public Health Nutr. 2001;4(5A):1117-1126.

17. Dibsdall LA, Lambert N, Bobbin RF, Frewer LJ. Low-income consumers' attitudes and behaviour towards access, availability and motivation to eat fruit and vegetables. Public Health Nutr. 2003;6(2):159-168

18. Blaxter M, Paterson E. Mothers and Daughters: A Three Generational Study of Health Attitudes and Behaviours. London: Heinemann; 1982

19. Townsend P, Davidson N, Black D. Inequalities in Health: The Black Report. Harmondsworth, UK: Penguin; 1992.

20. Pill R, Stott NC. Concepts of illness causation and responsibility: some preliminary data from a sample of working class mothers. Soc Sci Med. 1982;16(1):43-52.

21. Pill R, Stott NC. Choice or chance: further evidence on ideas of illness and responsibility for health. Soc Sci Med. 1985;20(10): 981-991.

22. Pill R, Stott NC. Preventive procedures and practices among working class women: new data and fresh insights. Soc Sci Med. 1985;21(9):975-983.

23. Stott NCH, Pill RM. Making Changes: A Study of Working Class Mothers and the Changes Made in Their Health Related Behaviours Over 5 Years. Cardiff, Wales: University of Wales College of Medicine; 1990.

24. Ritchie J, Spencer L. Qualitative data analysis for applied policy research. In: Bryman A, Burgess R, eds. Analyzing Qualitative Data. London: Routledge, 1994:173-194.

25. Goffman E. The Presentation of Self in Everyday Life. New York NY: Doubleday-Anchor; 1959.

26. Gough B, Conner MT. Barriers to healthy eating amongst men: a qualitative analysis. Soc Sci Med. 2006;62(2):387-395.

27. Roe L, Strong C, Whiteside C, Neil A, Mant D. Dietary intervention in primary care: validity of the DINE method for diet assessment. Fam Pract. 1994;11(4):375-381. 